\title{
The role of Basal HRV assessed through wavelet transform in the prediction of anxiety and affect levels: a case study
}

\author{
Marcio Magini $^{1}$, I zabela Mocaiber ${ }^{1}$, Leticia de Oliveira ${ }^{2}$, Welton Luiz de Oliveira Barbosa ${ }^{1}$, Mirtes \\ Garcia Pereira², Walter Machado-Pinheiro ${ }^{1}$ \\ 1. Department of Physics and Mathematics, Universidade Federal Fluminense, Brazil. 2. Department of Physiology and \\ Pharmacology, Fluminense Federal University, Brazil.
}

Correspondence: Marcio Magini. Address: Polo Universitário de Rio das Ostras, R. Recife s/n, Jardim Bela Vista, Rio das Ostras, Rio de Janeiro, 28890-000, Brazil. Telephone: 00-552-764-9037. Email: marcio.magini@pq.cnpq.br

Received: February 28, 2012

Accepted: April 22, 2012

Published: June 1, 2012

DOI : $10.5430 /$ jbgc.v2n1p133

URL: http://dx.doi.org/10.5430/jbgc.v2n1p133

\begin{abstract}
The present paper is a designed case study to understand the potential role of heart rate variability (HRV) to predict different levels of anxiety and affect in a non-clinical sample by Wavelet Transform Tools. Trait anxiety was evaluated through the Spielberger's State-Trait Anxiety Inventory. Positive and negative affect scores were measured through the Positive (PA) and Negative (NA) Affect Schedule. Electrocardiogram (ECG) was recorded during 4 min in basal conditions. The ECG data was analyzed using Wavelet Transform Daubechies order 4 as kernel. Our aim is investigate whether HRV, assessed by the wavelet transform decomposition in 8 levels of frequency, would be able to characterize trait anxiety (TA), PA and NA characteristics. Correlation analysis were conducted between each psychological parameter (TA, PA and NA) and the values of frequency levels. The results showed a weak but relevant tendency between frequency level and individual trait or affective score. Thus, the present study suggests that resting HRV is efficient to predict anxiety trait and affective trait and state. Beyond, the results points to the need of introducing different stimulations or tasks capable of modulating HRV and evidencing its association with distinct psychophysiological patterns.
\end{abstract}

\section{Key words}

Anxiety, Basal, Electrocardiogram, Wavelet, Significance analysis

\section{I ntroduction}

The heart rate is under a wide range of physiologic influences, but the autonomic nervous system (ANS) has been considered the most prominent factor. The ANS is generally conceived to have two major branches, the sympathetic system associated with energy mobilization and parasympathetic system associated with vegetative and restorative functions. The activity of these branches is in dynamic balance, supporting modern conceptions of organism function that hold that organism adaptability and health are maintained through variability in the dynamic relationship among system elements ${ }^{[1]}$. In this context, the analysis of heart rate variability (HRV) is valuable in demonstrating the implications of complex variability in the cardiovascular system. Heart rate variability results from the dynamic and homeostatic 
interaction of sympathetic and parasympathetic (vagal inputs) activity to the sino-atrial node indexing beat to beat differences in the length of the cardiac cycle over time ${ }^{[1]}$.

HRV data are consistent with the view that cardiovascular health is typically reflected in complex variability rather than strict periodicity ${ }^{[2]}$. In this sense, low HRV is associated with increased risk of all-cause mortality and has been proposed as a marker for disease ${ }^{[3]}$. Specifically, due to differential frequency characteristics of the sympathetic and parasympathetic heart rate neural modulation, spectral analysis of the heart rate time series allows us to examine such neural influences. Power spectrum analysis and classification assess the quantitative contribution to determine high frequency $(0.15-0.5 \mathrm{~Hz})$, low frequency $(0.04-0.15 \mathrm{~Hz})$ and very low frequency $(0.01-0.04 \mathrm{~Hz})$ components for $\mathrm{HRV}$ data collection. Modulation at frequencies from 0.04 to $0.15 \mathrm{~Hz}$ corresponds primarily to baroreceptor-mediated regulation of blood pressure and involves modulation by both sympathetic and parasympathetic (vagal) influences. Modulations at frequencies greater than $0.15 \mathrm{~Hz}$ are defined as high frequency component and have been interpreted as a marker of vagal activity ${ }^{[4]}$. It has been suggested that the heart is under tonic inhibitory control by the parasympathetic influences, favoring energy conservation by vagal dominance over sympathetic influences. In this vein, autonomic imbalance, in which the sympathetic system is hyperactive and the parasympathetic is hypoactive has been associated with pathological conditions. For example, reduction in parasympathetic innervation is considered to leave the heart exposed to unopposed stimulation by the sympathetic nervous system, and consequently vulnerable to ventricular arrhythmia and sudden death ${ }^{[5]}$.

HRV has also demonstrated a far reaching utility in the study of emotional processes and psychiatric conditions. Recent work has suggested that HRV can be used to measure physiological changes in a number of psychiatric illnesses such as major depression ${ }^{[6]}$, generalized anxiety disorder ${ }^{[1]}$ and post-traumatic stress disorder ${ }^{[7]}$. Melzig et al. investigated the relationship between fear potentiated startle (a mammalian defensive response) and HRV in panic disorders. Their results revealed that low resting HRV was associated with exaggerated startle responses to the threat of shock ${ }^{[7]}$. Another recent study investigated the HRV in healthy controls and in patients with different types of anxiety disorders (panic disorder, social phobia, generalized anxiety disorder) ${ }^{[8]}$. Standard deviation of the normal-to-normal intervals (SDNN), heart rate (HR), and respiratory sinus arrhythmia (RSA) were measured in subjects participating in The Netherlands Study of Depression and Anxiety (NESDA). Results showed that current anxious subjects had a significantly lower SDNN and RSA compared with controls, suggesting that anxiety disorders are associated with significantly lower HR variability ${ }^{[8]}$.

Other studies propose that low HRV may be a useful endophenotype, at least for some anxiety disorders ${ }^{[9]}$, which has been associated with increased risk for cardiovascular disorders including ventricular arrhythmia, myocardial infarction, heart failure and sudden death ${ }^{[10]}$. More recently, anxiety trait (TA - a risk factor for anxiety disorders that reflects individual differences in the sensitivity to threat) has been considered as an important predictor of cardiovascular disease and, interestingly, it would be mediated by differences in $\mathrm{HRV}^{[11,12]}$. On the other hand, others have pointed to the beneficial effects of positive emotion on health and longevity. Fredrickson and Levenson have found direct evidence that positive emotion can quicken cardiovascular recovery ${ }^{[13]}$. Dowd et al. investigated changes in both affect (positive and negative) and cardiovascular responding in the context of a public speaking task (experimental stress group) and a silent reading task (control group). The results indicated that Positive Affect (PA) and Negative Affect (NA) responded differently to the stressor and contributed independently to both cardiovascular responding and recovery. Of particular interest was the finding that higher levels of both PA and NA predicted greater cardiovascular recovery ${ }^{[14]}$.

In the present study, we employed the Wavelet transform and statistical tools to determine HRV patterns in individuals that differed in trait anxiety (TA), positive (PA) and negative affect (NA). Biological signals can be processed through different tools. Depending on their characteristics, results can be distinct and their interpretations may generate some possibilities of applications. For signals with periodic behavior, Fourier analysis is usually indicated. However, when the signal has non-periodic behavior this analysis is not indicated, requiring other processing tools. Wavelet has been successfully used to analyze biological signals and has been proved to be useful to mathematically describe data with 
non-periodic characteristics ${ }^{[15-17]}$. Therefore, we analyzed electrocardiographic (ECG) data collected from volunteers at resting conditions and applied the Wavelet transform Daubechies degree 4 to shift the original signal in three levels of frequency: high frequency (HF), low frequency (LF) and ultra-low frequency (ULF) tools. Specifically, we used Wavelet transform to investigate the association between cardiovascular functioning and TA, PA and NA levels.

\section{Material and methods}

\subsection{Subjects}

Thirty right-handed undergraduate students (15 female) with a mean age of 21.07 years $( \pm 1.68 \mathrm{SD})$ participated in this study. Volunteers were selected among students from the Federal Fluminense University, Brazil, and had normal or corrected-to-normal vision. They reported no psychiatric or neurologic problems and were not under medication with nervous system action. Participants were naive as to the purpose of the experiment. The local ethics committee approved the experiment, and participants gave informed consent. Participants were tested individually. On arrival, they completed the Portuguese trait section ${ }^{[18]}$ of the State and Trait Anxiety Inventory (STAI-T) ${ }^{[12]}$. This questionnaire consists of 20 short statements (e.g. "I feel afraid") rated on a four-point scale ( $1=$ seldom/never, $4=$ very often/always). It was used in order to characterize the sample in terms of trait anxiety (TA) levels. Volunteers also completed the trait and state version of the Positive and Negative Affect Schedule ${ }^{[19]}$ to measure positive (PA) and negative affect (NA). This scale consists of 20 adjectives describing different feelings and emotions, ten describe positive mood and ten describe negative moods. It was used to measure positive and negative affect trait and state in each subject.

\subsection{Procedure}

After completing the questionnaires, participants were seated in a chair located in a sound attenuated and dimly lit experimental room. They were informed about the nature of the assessments and written consent was obtained. Physiological sensors were attached and signal quality was checked before starting the physiological recordings. Subjects were instructed to rest and breathe normally. A Biopac ECG recorder, model MP100, was used to record the electrocardiogram at lead II using silver/silver chloride electrodes with hypertonic electrolyte paste. A band filter of 0.5-35 $\mathrm{Hz}$ and a sampling rate of $1000 \mathrm{~Hz}$ were used. During the $4 \mathrm{~min}$ of baseline assessment, ECG was analyzed using wavelet analysis.

\subsection{Wavelet analysis}

Wavelet is a powerful tool to analyze none or quasi periodic signals. It has been initially used to understand the probable periods of solar explosion. After applications in geophysics, the Wavelet was proposed to solve some problems in biological signal processing ${ }^{[20,21]}$, image processing, design patterns and adapted for biological signals. This adaptation was required because the patterns in the periodogram and the Global Wavelet Spectrum analysis were not sufficient to extract information about biological signals. Mathematically speaking the Wavelet Transform decomposes the function in time domain in a function in frequency domain, similarly to the Fourier Transform. The main difference is the input data, for the Fourier Transform the signal must be periodic and, from that, the frequencies are extracting. The Wavelet Transform creates the possibility to analyze non-periodic signal as ECG, for example, which is useful in biological applications. The Wavelet Transform of a continuous time signal $x(t)$, with respect to the wavelet function $\psi(\mathrm{t})$, is defined as:

$$
W_{\psi}(a, b)=\frac{1}{\sqrt{a}} \int_{-\infty}^{\infty} x(t) \psi^{*}\left(\frac{1}{b-a}\right) d t
$$

where $\psi^{*}$ is the complex conjugate of the analyzing wavelet function $(\psi)$ used in the coefficient convolution and $x(t)$ is a signal to be decomposed. The wavelet transform $W_{\psi}(a, b)$ can therefore be the cross of the analyzed signal with a wavelet function that has been translated by a parameter $b$ and dilated by a factor $a$. For our case the wavelet is easily discretized 
impose that $a$ and $b$ generates a lattice and it's called Discrete Wavelet Transform (DWT) ${ }^{[22]}$. DWT can decompose a signal in its time domain into time-frequency domain with expression of a set of translated and scaled version of a basis mother wavelet. It consists of a dyadic grid $a=2^{i}$ and $b=j \times b_{0} \times 2^{i}$ where $i, j \in \mathbb{Z}$. With $b_{o}=1$ the wavelet function $\psi(t)$ and $\phi(t)$ are respectively defined by equations (2) and (3).

$$
\begin{aligned}
& \psi_{i, j}(t)=2^{-\frac{i}{2}} \psi\left(2^{-i} t-n\right) \\
& \varphi_{i, j}(t)=2^{-\frac{i}{2}} \varphi\left(2^{-i} t-n\right)
\end{aligned}
$$

Through wavelet decomposition, any signal can separately pass through a series of complementary high pass filters as well as low-pass filters, which are down-sampled by 2 for generating the higher frequency coefficients (Details components) and lower frequency coefficients (Approximation component) at different scales, respectively. Approximation coefficients (lower frequency) can be further decomposed into next level approximation coefficients and detail until the desired resolution is reached for any application ${ }^{[23,24]}$, the frequencies are scaling in a power of 2 . In our case the decomposition in three different levels of frequency were implemented. From that, an additional tool was created to generate a procedure that calculates the values of significance of the signal. These values are important to provide information about data variability, energy levels and to inform whether the oscillations through the time are quasi or non-periodic. When the mean values are near zero and the variance cannot be used as parameter of comparison, it is necessary to use tools capable of extracting information like periodicity and frequency levels. Figure 1 show a boxplot obtained from the values of ECG data in basal condition for all volunteers. As we can see that there is no established pattern, deviations are not easily quantified and data dispersion is highly heterogeneous.

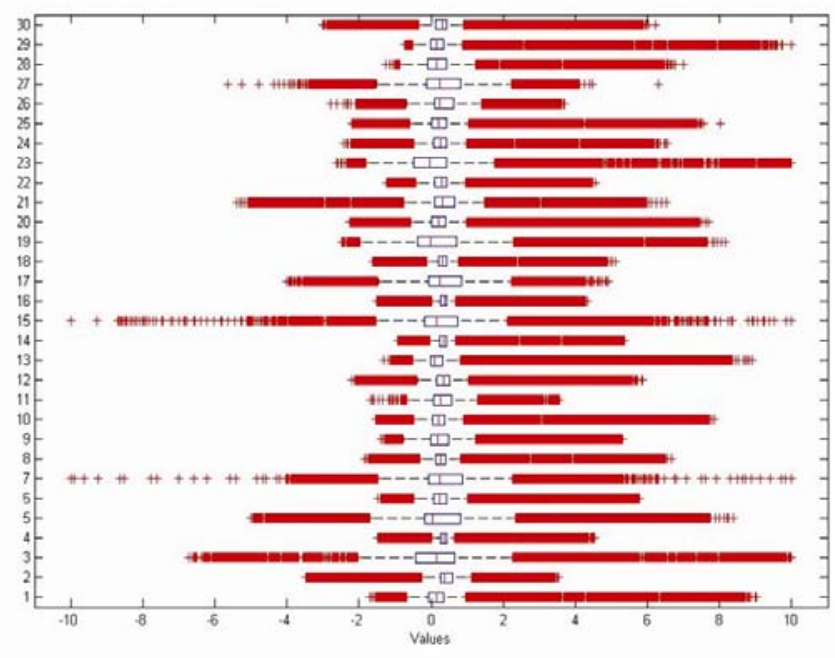

Figure 1. Boxplot of the ECG data in basal condition ( $N=30$ volunteers)

The wavelet can use a set of functions as kernel of transformation, which represents an advantage of this tool. Besides, the function can be used to describe any pattern in the existing data. When the signal is quasi-periodic and contains symmetric properties, some functions are more adequately analyzed by the Wavelet Kernel, specified by $(\psi)$. Specifically, in the present work we adapted the Wavelet analysis through Daubechies degree 4 to decompose the biological signal (ECG data) in 8 levels, where: levels 1, 2 and 3 correspond to high frequencies (HF); 4, 5 and 6 to low frequencies (LF); 7 and 8 to ultra-low frequencies (ULF). Figure 2 exemplifies the decomposition of the signal (resting ECG data) collected in this study in 8 levels. 


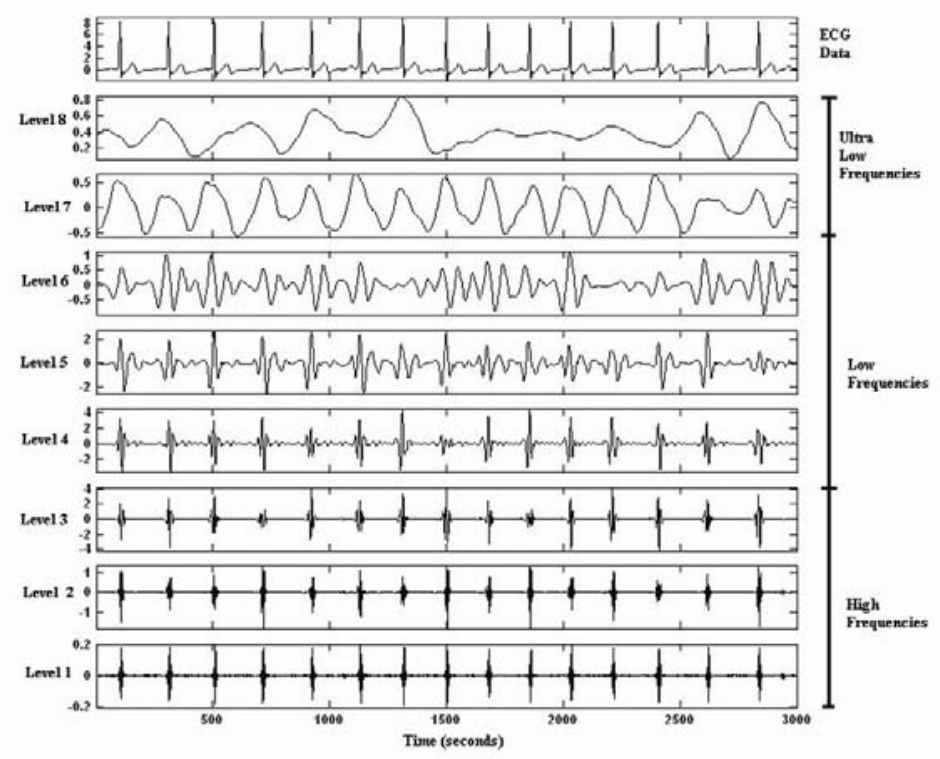

Figure 2. Example of ECG data decomposition in 8 levels divided in high, low and ultra-low frequencies using Daubechies degree 4 as $(\psi)$ function

From the statistical density, it was possible to calculate the area under the curve (AUC), which is useful to determine the contribution of each frequency level for HRV, after normalization. The total value of AUC for each level determines the $\mathrm{HRV}$ for each data. Figure 3 is a graphical example of this distribution.

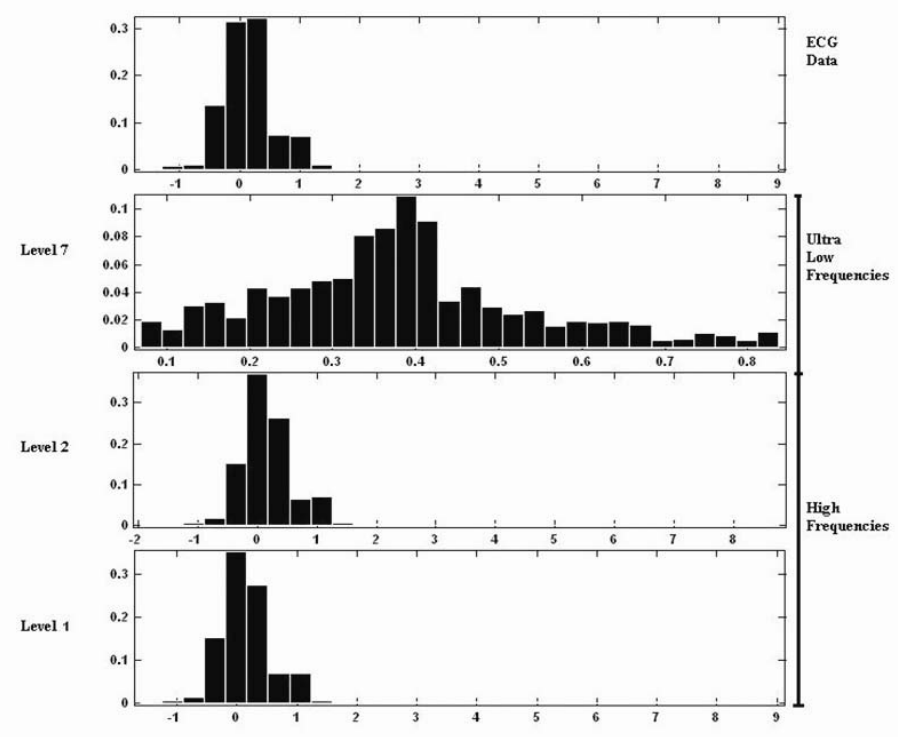

Figure 3. Example of statistical distribution in each level of frequency for one volunteer

The area was calculated extracting the values of each distribution. It is possible to compare the distribution in each frequency level with the main distribution (top row): high frequencies have a major contribution to the fundamental 
pattern of the total distribution. Low and ultra-low frequencies are less relevant, allowing a strong association between high frequencies and the general pattern of ECG data.

\section{Results}

Table 1 presents the correlation coefficient between each psychological variable [trait anxiety (TA), positive (PA) and negative (NA) affect trait and state] and values obtained in each frequency level [level 1 (HF), level 2 (HF), level 7 (ULF) and the difference between HF and ULF]. In bold font, it is possible to notice the correlations between high frequencies and TA and NA (state). The main interest is to observe the changes in the angular signal coefficient which determines the HRV relations, for example: when the signal is positive it means that the variability in each frequency level increases as a function of a psychological variable. On the other hand, negative values indicate that the psychological scores are inversely correlated to the variability in each frequency level. The former pattern can be observed for the correlation between TA and HF (levels 1 and 2); and NA (state) and HF (levels 1 and 2). Thus, TA and NA are associated with the increase of variance in HF (levels 1 and 2).

Table 1. Correlations values among the different psychological scores and variability in each level of frequency

\begin{tabular}{llllll}
\hline Frequencies & \multirow{2}{*}{ TRAIT anxiety (TA) } & $\begin{array}{l}\text { TRAIT } \\
\text { NA }\end{array}$ & $\begin{array}{l}\text { TRAIT } \\
\text { PA }\end{array}$ & $\begin{array}{l}\text { STATE } \\
\text { NA }\end{array}$ & $\begin{array}{l}\text { STATE } \\
\text { PA }\end{array}$ \\
\hline Level 1 (HF) & $\mathbf{0 . 0 3 6 0 6}$ & -0.00400 & -0.08132 & $\mathbf{0 . 2 7 8 7 3}$ & 0.07558 \\
Level 2 (HF) & $\mathbf{0 . 0 5 4 4 3}$ & -0.02267 & -0.11200 & $\mathbf{0 . 2 8 9 4 4}$ & 0.05610 \\
Level 7 (ULF) & -0.04295 & -0.07626 & -0.15502 & -0.16475 & 0.04154 \\
HF-ULF (\%) & -0.09770 & -0.07567 & -0.16183 & -0.27722 & 0.00908 \\
\hline
\end{tabular}

In Table 2 it's showed the $p$-values for each frequency level variance and for the difference between HF and ULF. The $p$-values, in this case are not representative for most of measures but, it is possible to see the bold values representing low $p$-values specifically: 0.16 for HF-ULF (\%), relevant differences in STATE NA, where most of $p$-values are below than 0.2 . These values can be interpreted as a tendency in the behavior of the HRV for patients anxious and non-anxious. In a mathematical approach by linear regression this tendency is observed.

Table 2. $P$ - values among the different psychological scores and variability in each level of frequency

\begin{tabular}{llllll}
\hline Frequencies & TRAIT anxiety (TA) & $\begin{array}{l}\text { TRAIT } \\
\text { NA }\end{array}$ & $\begin{array}{l}\text { TRAIT } \\
\text { PA }\end{array}$ & $\begin{array}{l}\text { STATE } \\
\text { NA }\end{array}$ & $\begin{array}{l}\text { STATE } \\
\text { PA }\end{array}$ \\
\hline Level 1 (HF) & 0.84 & 0.83 & 0.66 & 0.13 & 0.69 \\
Level 2 (HF) & 0.77 & 0.90 & 0.55 & 0.12 & 0.76 \\
Level 7 (ULF) & 0.82 & 0.68 & 0.41 & 0.38 & 0.82 \\
HF-ULF (\%) & 0.16 & 0.69 & 0.39 & 0.13 & 0.96 \\
\hline
\end{tabular}

Figures 4 and 5 present the linear approach where it is possible to notice the differences between the angular coefficients. Regarding negative affect (NA) state, the correlation coefficient assumes the value 0.27873 for level 1 and -0.16475 for level 7 (ultra-low frequency). The weak correlation (or the low correlation value) does not represent an insignificant value for physiological interpretation. Actually, the angular coefficient signal resulted from the entire data collection can be interpreted as follows: The change in signal direction for different levels of frequency is important information about the role of variance (HRV) in each frequency level and its relation with different psychological variables. Here, negative state (NA) is positively related to the variance in the HF domain and negatively correlated with the variance in the ULF domain. Thus, higher NA score is associated with more variance in the HF domain. On the other hand, higher NA is associated with less variance in ULF levels. 


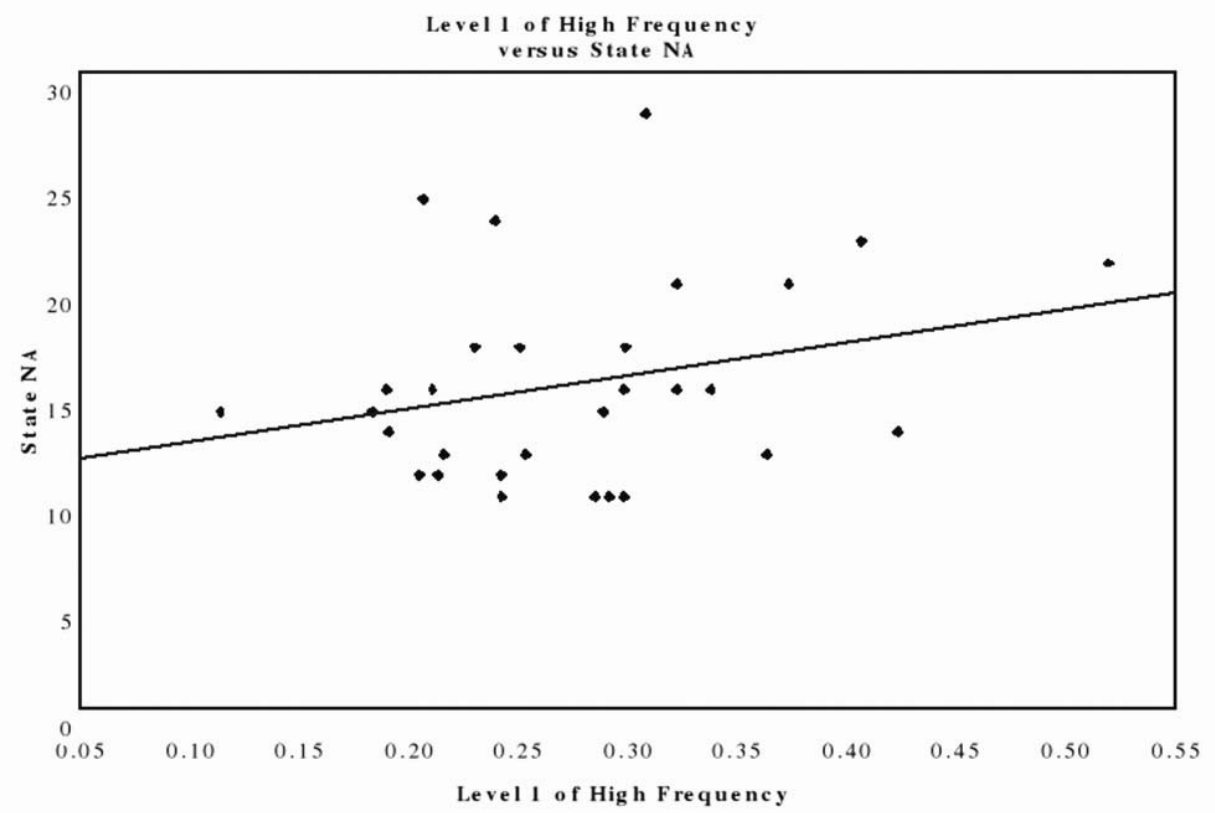

Figure 4. Negative Affect State versus Level 1 with linear regression approach $(n=30)$

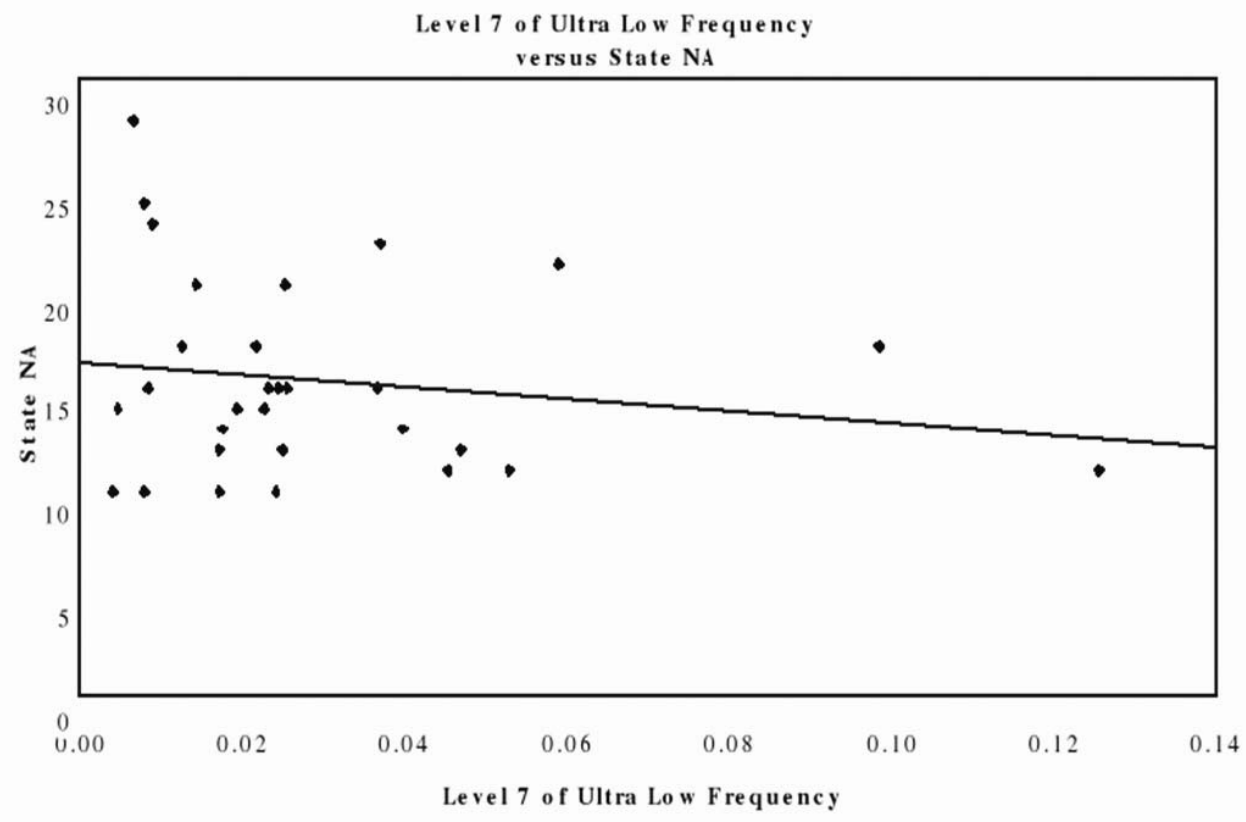

Figure 5. Negative Affect State versus Level 7 with linear regression approach $(\mathrm{n}=30)$

An additional analysis is presented in Figure 6. It shows the correlation between the total variance of each volunteer and its relation with positive affect (PA) state scores (not presented in Table 1) - the angular coefficient for this linear regression is -0.3176 . Higher PA scores are associated with less variability in total variance. 


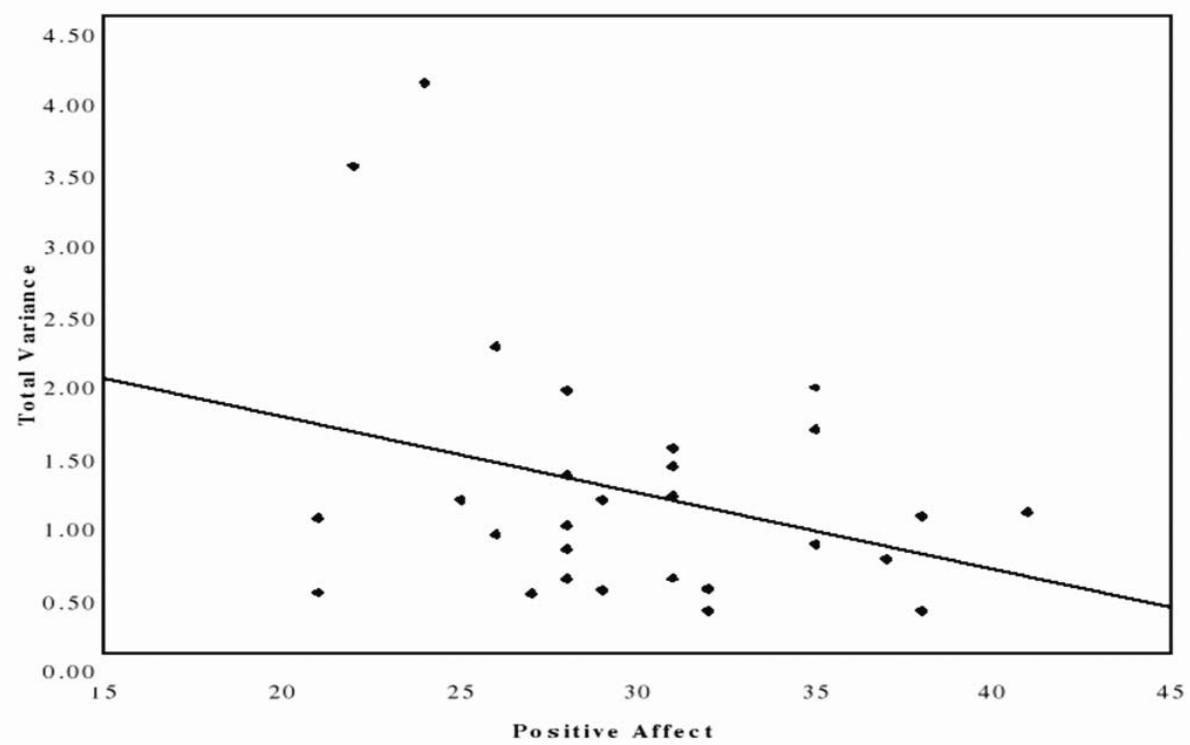

Figure 6. Values of total variance of each volunteer versus state of positive affect $(n=30)$

Remember that the original ECG signal pattern is mainly defined by the high frequencies (see Figure 3). Thus, the total variance values can be interpreted as a predominantly consequence from HF patterns. It means that higher PA scores are related to less variance in HF domain.

\section{Discussion}

In the present study we investigate the potential role of wavelet transform to predict the relation among HRV, anxiety, affect trait and state. This analysis resulted in three important findings: TA was weakly related to variance in each frequency level; negative affect state (NA) tended to positively correlate to variance in the HF domain (equivalent to level 1 and 2 in Wavelet decomposition) and positive affect state (PA) tended to correlate inversely to the total variance.

Regarding TA, it has been interpreted as a risk marker for anxiety disorders. Reduced HRV has been empirically supported in anxiety and affective disorders. For instance, several studies reported that HRV is reduced in patients with panic disorder ${ }^{[25,26]}$. This relation has been assessed during a variety of laboratory conditions (e.g. stressful tasks). In the present study, we observed that the possible direction of this association would be positive, which means that higher TA scores would be associated with more variance in the HF domain, which is an index of vagal influence. According to this, a significant association between TA and variance in HF domain would be consistent with the existing literature, which emphasizes that reduced HRV (indexed by HF) is related to anxiety disorders ${ }^{[27,28]}$.

Fueler et al. also investigated the association between TA and HRV differences. They found reduced heart rate and increased LF and HF power in low TA compared to high TA participants ${ }^{[28]}$. However, other studies failed to show such pattern ${ }^{[16,27]}$. Cohen et al., for example, showed that post-traumatic stress disorder (PTSD) patients had similar total HRV power, compared with case-controls ${ }^{[29]}$. Another study failed to show a significant association between anxiety trait scores and absolute HF component ${ }^{[30]}$. A previous work investigated the role of hostility and anxiety in cardiovascular function and found no association between these psychological factors and HRV ${ }^{[31]}$, yielding non consistent results. In fact, some studies have not found a significant association between TA and HRV, leaving this question still open and controversial. However, our study points to the possibility, from ECG measures, to understand the general relation between variability and affect states. 
Regarding positive and negative affect scores, the most relevant results in the present study were the directions of the relations observed. Negative affect state was positively correlated to variance in HF domain. As the HF domain almost completely describes the original ECG signal, it can be interpreted as the total HRV parameter. In this case, individuals who scored higher in NA exhibited a diminished contribution of the HF domain (larger variance) to the whole ECG signal, which we interpret as a reduced HRV. One possible limitation of the lack of significance was the experimental design employed here: normal volunteers had their ECG signal recorded during resting conditions. However, existing data have shown that emotions have their greatest influence on cardiovascular health when the person is under stress ${ }^{[32]}$. Additionally, a specific study showed that (PTSD) patients failed to exhibit the expected elevation in HR and low frequency component of HRV even during recounting traumatic events, highlighting the need for more adequate protocols to assess the relation between psychological states and HRV, for example, using provoking.

Concerning positive affect state (PA), as showed in Figure 6, it was inversely related to the total signal variance, which is mostly described by HF (this frequency level determine the main pattern of the original signal). This means that individuals who scored higher on PA state exhibited reduced variance in the total signal (reduced variance in the HF domain), which could be ultimately interpreted as a more consistent HF acting (higher HRV). Frederickson and Levenson found direct evidence that positive emotions can quicken cardiovascular recovery ${ }^{[9]}$. More recently, Dowd et. al. investigated the effects of stress on the experience of positive and negative affect and the effects of effect on cardiovascular reactivity and recovery. It was shown that for participants delivering a speech to camera PA and NA both contributed to the prediction of cardiovascular reactivity and recovery. Higher PA was associated with greater systolic blood pressure reactivity ${ }^{[5]}$.

Thus, the present case study shows that the set of tools proposed were adequate to predict associations between psychological variables and HRV. The tools allowed the description of the general pattern of the signal, leading us to explore the relations between TA, NA, PA and HRV. Importantly, the specificity of each condition can be overwhelmed by more adequate paradigms, such as stress provocation or pharmacological manipulation, which more accurately taps on HRV alterations. Also, this potential application would possibly benefit from more provoking paradigms, which are more sensitive to HRV fluctuations and can be applied directly in patients that demands subjective diagnosis of anxiety based in forms and ECG data. For this, the proposed methodology must be verified in larger data basis, since the wavelet parameters are better adjusted when the sample number of patients increases.

\section{References}

[1] Thayer JF, Friedman BH, Borkovec TD. Autonomic characteristics of generalized anxiety disorder and worry. Biol Psychiatry. 1996; 39: 255-266. http://dx.doi.org/10.1016/0006-3223(95)00136-0

[2] Appel MV, Berger RD, Saul JP, Smith JP, Cohen RJ. Beat-to-beat variability in cardiovascular variables: noise or music? J Am Coll Cardiol. 1989; 14: 1139-1148. http://dx.doi.org/10.1016/0735-1097(89)90408-7

[3] Task Force of the European Society of Cardiology and the North American Society of Pacing Electrophysiology. Heart rate variability: standards of measurement, physiological interpretation, and clinical use. Circulation. 1996; 93: 1043-1065. http://dx.doi.org/10.1161/01.CIR.93.5.1043

[4] Stein PK \& Kleiger RE. Insights from the study of heart rate variability. Annu Rev Med. 1999; 50: 249-261. PMid:10073276 http://dx.doi.org/10.1146/annurev.med.50.1.249

[5] Bigger Jr, JT, Fleiss JL, Steinman RC, Rolnitzky LM, Kleiger RE, Rottman JN. Frequency domain measures of heart period variability and mortality after myocardial infarction. Circulation. 1992; 85: 164-171. PMid:1728446

[6] Rechlin T, Weiss M, Spitzer A, Kaschka WP. Are affective disorders associated with alterations of heart rate variability? J Affect Disord. 1994; 32:271-275. http://dx.doi.org/10.1016/0165-0327(94)90091-4

[7] Melzig CA, Weike AI, Hamm AO, Thayer JF. Individual differences in fear potentiated startle as a function of resting heart rate variability: implications for panic disorder. Int J Psychophysiol. 2009; 71:109-117. PMid:18708100 http://dx.doi.org/10.1016/j.ijpsycho.2008.07.013

[8] Licht CM, de Geus EJ, van Dyck R, Penninx BW. Association between anxiety disorders and heart rate variability in The Netherlands Study of Depression and Anxiety (NESDA). Psychosom Med. 2009; 71: 508-518. PMid:19414616 http://dx.doi.org/10.1097/PSY.0b013e3181a292a6 
[9] Friedman BH, Thayer JF. Autonomic balance revisited: panic anxiety and heart rate variability. J Psychosom Res. 1998; $44: 133-151$. http://dx.doi.org/10.1016/S0022-3999(97)00202-X

[10] Gorman JM, Sloan RP. Heart rate variability in depressive and anxiety disorders. Am Heart J. 2000; 140: 77-83. PMid:11011352 http://dx.doi.org/10.1067/mhj.2000.109981

[11] Mocaiber I, Pereira MG, Erthal FS, Figueira I, Machado-Pinheiro W, Cagy M, et al. Regulation of negative emotions in high trait anxious individuals: an ERP study. Psychol Neurosci. 2009; 2: 211-217. http://dx.doi.org/10.3922/j.psns.2009.2.014

[12] Spielberger CD. Manual for the State-Trait anxiety Inventory. Consulting Psyhologists Press, Palo Alto.1993.

[13] Frederickson BL, Levenson RW. Positive emotions speed recovery from the cardiovascular sequel of negative emotions. Cogn Emot. 1989; 12:191-220. http://dx.doi.org/10.1080/026999398379718

[14] Dowd H, Zautra A, Hogan M. Emotion, Stress and Cardiovascular response: an experimental test of models of positive and negative affect. Int J Behav Med. 2012; 17:189-194. PMid:19763841 http://dx.doi.org/10.1007/s12529-009-9063-3

[15] Machado SM, Osório RAL, Silva N S, Magini M. Biomechanical analysis of the muscular power of martial arts athletes. Medical \& Biol Eng \& Comp. 2010; 48: 573-577. http://dx.doi.org/10.1007/s11517-010-0608-z

[16] Malloy PF, Fairbank JA, Keane TM. Validation of a multimethod assessment of post-traumatic stress disorders in Vietnam veterans. J Consult Clin Psychol. 1983; 51: 488-494. PMid:6619355 http://dx.doi.org/10.1037/0022-006X.51.4.488

[17] Paiva JPLM, Kelencz CA, Paiva HM, Galvão RH, Magini M. Adaptive wavelet EMG compression based on local optimization of filter banks. Physiol Meas. 2008; 29: 843-856. PMid:18583726 http://dx.doi.org/10.1088/0967-3334/29/7/012

[18] Gorenstein C, Andrade L. Validation of a Portuguese version of the Beck depression inventory and the State-trait inventory in Brazilian subjects. Braz J Med Biol Res. 1997; 29: 453-457.

[19] Watson D, Clark LA, Tellengen A. Development and validation of brief measures of positive and negative affect: the PANAS scales. J Pers Soc Psychol. 1998; 54: 1063-1070. PMid:3397865 http://dx.doi.org/10.1037/0022-3514.54.6.1063

[20] Neto OP, Magini M. Electromiographic and kinematic characteristics of Kung Fu Yau-Man palm strike. J Elect Kinesiol. 2007; 18: 1047-1052. PMid:17499517 http://dx.doi.org/10.1016/j.jelekin.2007.03.009

[21] Maitrot A, Lucas MF, Doncarli C, et al. Signal-dependent wavelets for electromyogram classification. Med \& Biol Eng \& Comp. 2005; 43: 487-492. http://dx.doi.org/10.1007/BF02344730

[22] Rao RM, Bopardikar AS, Wavelet Transform - Introduction to theory and applications, Pearson Education Inc., India, 2000.

[23] Strang G, Nguyen T, Wavelets and Filter Banks, Wellesley-Cambridge Press, Cambridge, 1996.

[24] Pichot V, Gaspoz, JM, Molliex S, Antoniadis A, Busso T, Roche F, et al. Wavelet transform to quantify heart rate variability and to assess its instantaneous changes. J Appl Physiol. 1999; 86: 1081-1091. PMid:10066727

[25] Srinivasan K, Ashok MV, Vaz M, Yeragani VK. Decreased caos of heart rate time series in children of patients with panic disorder. Depress Anxiety. 2002; 15:159-167. PMid:12112720 http://dx.doi.org/10.1002/da.10046

[26] Sullivan GM, Kent JM, Kleber M, Martinez JM, Yeragani VK, Gorman JM. Effects of hyperventilation on heart rate and QT variability in panic disorder pre and post treatment Psychiatry Res. 2004; 125: 29-39. PMid:14967550 http://dx.doi.org/10.1016/j.psychres.2003.10.002

[27] Dishmann RK, Nakamura Y, Garcia ME, Thompson RW, Dunn AL, Blair SN. Heart rate variability, trait anxiety, and perceived stress among physically fit men and women. Int J Psychophysiol. 2000; 37: 121-133. http://dx.doi.org/10.1016/S0167-8760(00)00085-4

[28] Fuller BF. The effects of stress anxiety and coping styles on heart rate variability. Int J Psychophysiol. 1992; 12:81-86. http://dx.doi.org/10.1016/0167-8760(92)90045-D

[29] Cohen H, Benjamin J, Geva AB, Matar MA, Kaplan, Z, Kotler M. Autonomic dysregulation in panic disorder and in post-traumatic stress disorder: application of power spectrum analysis of heart rate variability at rest and in response to recollection of trauma or panic attacks. Psychiatry Research. 2000; 96: 1-13. http://dx.doi.org/10.1016/S0165-1781(00)00195-5

[30] Narita K, Murata T, Hamada T, Takahashi T, Omori M, Suganuma N, Yoshida H, Wada Y. Interactions among higher trait anxiety, sympathetic activity and endothelial function in the elderly. J Psych Res. 2007; 41: 418-427. PMid:16494899 http://dx.doi.org/10.1016/j.jpsychires.2006.01.003

[31] Virtanen R, Jula A, Salminen JK, Voipio Pulkki LM, Helenius H, Kuusela T, Airaksinen J. Anxiety and hostility are associated with reduced baroreflex sensitivity and increased beat-to-beat blood pressure variability. Psychosom Med. 2003; 65: 751-756. PMid:14508016 http://dx.doi.org/10.1097/01.PSY.0000088760.65046.CF

[32] Zaura AJ. Emotions, stress and health. Oxford: Oxford University Press. 2003. 